\title{
DIDACTIC MODEL BASED ON PRINCIPLES OF CRITICAL THINKING
}

\author{
Irina Kazuša \\ Rīga Stradiṇš University, Latvia
}

\begin{abstract}
In Rìga Stradiņ̌̌ University chemistry study process is developed by researching different pedagogical approaches and didactic models and their application methods in order to filter out the least effective ones. The aim of this research is the development of a didactic model of the medical chemistry course. As a result of this research, it was concluded that the most suitable didactic model is the one based on principles of critical thinking. Critical thinking principles behind this didactic model are purposefulness, information selection and analysis, critical reading and note-making, fundamental regularity spotting and awareness of one's own knowledge limitations. These principles raise their level of individual work culture by emphasizing responsibility for their choices and decisions are taken and also develop dialogue culture and tolerant attitude towards others. Suitability of methods based on critical thinking principles and their combinations depend on reachable goals. Reading, lectures, and the use of online resources are effective for obtaining knowledge, solving problems and involving students in the cognition process but are less suitable for developing skills and gaining experience. Discussions and practical exercises, on the other hand, are suitable for gaining study experience and developing skills and reflection. By mastering critical thinking principles, students learn to understand the specific situation from different aspects, to generalize and to carry over understanding from familiar situations to new.
\end{abstract}

Keywords: critical thinking principles, higher education didactics, pedagogic methods.

\section{Introduction}

Preparation of experts in higher medical education system occurs in an environment where the high rate of development in the industry and constant knowledge updates can mean that scientific innovations lose their relevance before they have become a part of study material. Due to this, nowadays it is necessary in medical education to introduce concepts and technologies that promote the stabilization of student's personal position in the self-dependent study process and professional development. After mastering theoretical disciplines in the first year of studies, clinical simulations can be interesting, even though not suitable for student's actual level of qualification. In medical education - as in any other professional education - theoretical disciplines are mostly detached from real situations that will occur during professional work. Students are conscious of 
the fact that obtained theoretical knowledge will only partly be used in their work thus reducing their motivation to master chemistry.

Motivation can be stimulated by showing the potential for integrating medical chemistry in other theoretical and clinical courses thereby helping students to form a systemic approach and guiding them towards cognition of connections. It is necessary to create a study environment that functions as an integrated educational technology combining different study forms and methods with theoretical content of study material. The developed and approbated didactic model is a combination of study content and methods and is based on critical thinking principles: the principle of purposefulness, the principle of information selection and analysis, identification of the most important ideas when reading and writing, the principle of fundamental regularities and differentiation of facts from interpretations, opinions or prejudice and principle of understanding one's knowledge limitations.

The research was carried out in Rīga Stradiňš University (RSU) in the medical chemistry course during the first year of studies. Within a period of six years (2012-2018), 1272 respondents were surveyed. Experimental and control groups weren't selected since effectiveness was determined by the success of all students. The research was carried out by comparing the obtained data in the beginning and the end of the semester. Based on the results of the research, it can be stated that student's elementary critical thinking skills (how to identify a problem, how to put forward evidence or arguments, how to identify contradictions and deficiencies in fact selection or use in problem solutions) can be effectively developed using medical chemistry course material as a context.

\section{Literature review}

The phenomenon of critical thinking in the context of education has evolved into two relatively independent forms, one of which realizes critical thinking development directly i.e. as a separate subject in school, while the other indirectly, meaning that it is an interleaving skill in the study process (Rubene \& Svece, 2018). In order to teach doctors critical thinking one of two strategies must be chosen: 1) general studies on a philosophical level; 2) use of critical thinking in medicine together with other practical and scientific methods of healthcare (Jenicek, 2006). In accentuated critical thinking methods the principles of critical thinking are clearly formulated but in non-accentuated critical thinking methods the principles of critical thinking are integrated in course material without additional emphasis. Didactic model includes context-independent nonaccentuated methods based on critical thinking principles that are intended for mastering medical chemistry course. 
Critical thinking needs to be considered as a philosophical approach that is applicable in both psychological and sociological research as well as education. Like any other approach, it is based on certain principles and value orientation that is realized in a practical way. From many critical thinking development principles given in the literature, only certain were selected - those that are relevant for first-year students and can be realized in all situations of medical chemistry course and can be universally applied in future study process or professional work.

Basic critical thinking principles can partly be divided into two groups: 1) philosophical or general scientific principles and basic psychological principles; 2) specific instrumental principles (Volkov, 2004). Since the goal of the research is the development of the didactic model for medical chemistry course which is realized using methods based on critical thinking principles, the general principles weren't emphasized although they are present in the study course on a basic level.

Principles link basic concepts with specific methods or strategies. Development of basic concept is easier than transforming it into specific “principles” (Paul, Binker, Douglas, \& Adamson, 1989). The development of the didactic model is based on several principles postulated by R. Paul and L. Elder (Paul \& Elder, 2011; Elder \& Paul, 2012).

1. One of the basic critical thinking principles is orientation towards a certain goal. Students who think critically seek to understand not only what they are learning but why. They formulate purposes, goals, and objectives that are clear and reasonable (Paul \& Elder, 2011). Study process in university means setting clear goals and deciding how to reach them. Goals can be both short-term and long-term and they must motivate students to reach the desired study result.

2. Principle of information selection and analysis. Students who think critically seek the information relevant to the questions they are trying to answer and problems they are trying to solve while also analyzing and assessing information used by others. Thinking can be as true as the information it is based on (Paul \& Elder, 2011). When analyzing arguments, critical thinkers use analytical instruments in order to assess their relative advantages or deficiencies and to adapt the information for the context of study material.

3. Critical thinkers recognize problematic concepts and distinguish facts from interpretations, opinions, judgments or theories (Paul \& Elder, 2011). Students who think critically understand that humans often use distorted concepts and recognize bias and negation of fundamental regularities with a goal of manipulating others. Critical thinkers can distinguish justified assumptions from unjustified stereotypes. 
4. Critical thinkers are conscious of their knowledge limitations. It is the principle of intellectual humility (Elder \& Paul, 2012). Intellectual humility entails consciousness of one's biases disclosure of erroneous concepts, illusions and myths. Critical thinkers recognize their mistakes and change their opinion when confronted with more competent argumentation.

5. When reading texts, critical thinkers identify and apply the most important ideas. Critical thinkers use writing as an instrument for better understanding of concepts in texts (Paul \& Elder, 2012). By recognizing that each text has its purpose an inner dialogue with the text is made while summarizing the most important ideas.

Critical thinking principles allow systemic development of student's critical thinking within chemistry lessons, assist in determining one's priorities in study process, develops student's ability to generalize, analyze and draw conclusions, increases the level of culture of individual work with information, accentuates accountability for one's choices and decisions, develops dialogue culture as well as tolerant attitude towards others.

The aforementioned principles are applicable to fundamental basic philosophical and psychological rules as well as specific instrumental actions that can be realized as critical thinking methods suitable for different situations. Lecturers must be prepared to apply different combinations of pedagogic methods in situations when students have difficulties grasping or understanding information. No single set of learning principles will help everyone in every situation especially since students learn and remember only what they deem relevant to their chosen profession. Since the didactic model is based on a system of certain principles, they serve as guidelines that can affect pedagogic work and make the study process more productive.

In the beginning of the study process it is important to develop learning strategies that would ensure further education and professional development. The use of different study methods broadens student knowledge, activates cognition and helps to perceive information in a more interesting way while tying knowledge in chemistry with medical profession.

\section{Methodology}

Critical thinking skills that are based on logical, investigative and analytical thinking can be considered as preconditions for promoting cognition, however part of RSU Medicine faculty first year students do not have sufficient knowledge base and social experience to transform gained knowledge and skills into competence. Such thinking skills are to be developed in each field separately using methods specific for each study subject. They can be accentuated or non- 
accentuated critical thinking methods that complement each other and thus often cannot be completely separated from one another. Accentuated critical thinking methods clearly formulate critical thinking principles while non-accentuated critical thinking methods integrate critical thinking principles in course material. The didactic model is based on critical thinking principles and includes contextindependent non-accentuated methods that are intended for mastering medical chemistry course and are based on critical thinking principles:

- Study material outline for critical thinking development through information analysis;

- $\quad$ Graphic information organizers as method for structuring information;

- Development of critical thinking by engaging students in discussions;

- $\quad$ Problem situation analysis and problem task solution;

- Methods for developing self-assessment.

Critical thinking as methodology is boundless - it can be applied in any branch of science and can be approbated for specific needs (Rubene \& Svece, 2018). In the developed and practically verified didactic model the chemistry course material and methods based on critical thinking are made interdependent. The developed model is a flexible structure that is adaptable for variable situations.

\section{Study material outline for critical thinking development through information analysis}

Information analysis as a didactic method organizes information by making it logical and accessible. Work with information is based on critical thinking principles of the developed didactic model: principle of information selection and analysis; fact separation from interpretations and opinions; consciousness of one's own knowledge limitations and principle of transparency which is one of basic didactic principles. Today's generation of students are characterized by a new culture of perception which has formed as a response to ever-growing diverse, heterogeneous flow of information mostly in visual form. At the same time students are incapable of perceiving linear and homogeneous information including books.

L. Floridi sees three aspects of information: resource aspect, product aspect and goal aspect. Information as a resource implies its use in order to create a product. Information as a goal entails considerations of information use for particular purposes (Floridi, 2010). External information enters cognitive system via sensory mechanisms but internal information is a result of constant, dynamic and interactive interaction and integration of multiple interdependent subsystems (perception, attention, exertion) (Tennyson, 2013).

Ability to reproduce, understand and evaluate texts and argumentations is the main competence in any profession. The didactic model for mastering 
chemistry course is based on critical thinking principles and implies consecutive steps for analyzing texts.

Within medical chemistry course many texts are adapted for three phase critical thinking development model: initiation, comprehension, reflection:

- Initiation (experience systematization) phase is when students actualize previous knowledge about a study subject, determine missing knowledge, incorporate research elements in a logical chain of reasoning and determines individual goals in this research or problem solution.

- Comprehension (accomplishment of individual goals) phase is when students assess the new material and form a personal view of it and evaluate proof and arguments necessary for discussing the subject.

- Reflection (formation of personal position) phase is when students completely understand the nature of the subject, are capable of analyzing own thoughts, causes of the phenomenon and can predict the results. In this phase students also draw conclusions about what was accomplished, analyze mistakes and personal effort. Reflection phase entails content analysis, creative processing and information interpretation while keeping in mind that the same text can be rated differently.

R. Paul classifies reading as a macro-skill since reading implies coordination of multiple micro-skills in order to gain an understanding of the text (Paul, 1990). Critical reading is one of the strategies of how students can have a meaningful reading experience (Manarin et al., 2015) by understanding what is written, analyzing the string and weak points and contemplating potential ways for improvement (Fairbairn \& Winch, 2011). Critical reading is text analysis by evaluating described ideas and provided assumptions and their effects and recognizing logical contradictions. Written summarizing not only gives a clearer understanding of the text by incorporating one's own ideas and experience in written form but also allows referring to one's own thoughts later on. Chemistry worksheets help students by providing ideas for note writing. Worksheets can be used during different stages in lessons. They help to activate students in the initiation phase, help to organize productive and independent work during comprehension and synthesis phase and help analyzing one's own mistakes during reflection phase while also providing feedback.

Graphic information organizers as method for structuring information

Visualization as one of the methods of information analysis was used in chemistry course and its potential use in the study process was evaluated. Visual means aid in information search and make it more effective by creating a systemic approach oriented towards cognition of connections and awareness of missing knowledge which in essence is realization of critical thinking principles in study 
process. Visual means are used for illustrations, text summarization or graphical representation of experimental data. Visual proficiency gained in chemistry course can be applied not only in chemistry course but other domains as well when students understand their universal nature.

\section{Development of critical thinking by engaging students in discussions}

Discussions and dialogues as didactic methods transform work environment from passive to active and motivates students to independently search for solutions, listen and evaluate other opinions and critically analyze arguments.

Argumentation as competence entails student's skills and capabilities to understand spoken and written argumentation in different professional contexts while creating own arguments and adequately reacting to argumented verdicts of others (Budke \& Meyer, 2015). Lessons in discussion form require a welldisposed setting in order to stimulate student ability and need to effectively use different methods of argumentation. It is necessary to concentrate on the most important points of the discussed topic while integrating critical thinking skills into discussion to make it as productive as possible.

Discussion of different cases allows students to analyze new facts with lecturers and peers and allows identifying lack of specific knowledge thus gaining higher level cognitive skills in medical fact evaluation and interdisciplinary integration (Thomas \& Abras, 2016). In this way new information can be comprehended and contemplated according to one's personal rate of development.

\section{Problem situation analysis and problem task solution}

The didactic model based on critical thinking principles uses problem task solving for better comprehension of study material while also promoting the use of different cognition methods when constructing new knowledge, argumenting evidence or explaining causes of errors. Problem solving is one of several critical thinking development methods used in the didactic model - one which creates a desire to use previously learned facts and concepts in new situations. By learning specific steps of the solution, students realize that problem solving and critical thinking skill development are interdependent. Student abilities to define the problem, propose a hypothesis, obtain and evaluate information, predict results of problem solution, decide on clear solution steps and their potential outcomes are all developed through the semester. When reflecting on problem solution, students must understand the possible errors and fix them independently or with the help of others.

Learning by solving problems teaches to study since students that learn how to solve problems also develop a certain autonomy in resource selection (Cockerham, Dingwall, \& Quah, 2014). Prerequisites for finding a solution are facts, experience, confidence and assumptions that need to be combined to reach a conclusion (Kallet, 2014). 
Problem solving is a process where it is necessary to overcome known or unknown obstacles between the current state and the desired goal. In general it is an unknown situation or the solution is not known from previous experience. Decision making on the other hand is a selection process when one of several possible solutions must be chosen in order to reach the desired goal (Huitt, 1992). The didactic model based on critical thinking principles anticipates problem solving to ensure comprehension of study material in addition to developing cognitive method usage skills when constructing new knowledge, explaining errors and their causes or absurd assumptions.

\section{Methods for developing self-assessment}

In an evaluation system evaluation isn't just a means to assess knowledge, abilities and their usage skills since the evaluation process including selfassessment in itself is important. Student ability to evaluate their work methods and results must become a sustainable need and an integral part of their study skills when reflecting on their results. Due to this it is a lecturers task to employ an effective evaluation process that in addition to providing controlling function also includes a two-way communication between teaching staff and students. At the beginning of the study process lecturers have the leading role since students lack experience in organizing their study process. The intensity of the study process in university is significantly different from that of the student's previous experience in school. During the first year of studies, students often lack experience in self-organization and they do not understand their individual responsibility for study results. Because of this at the beginning of studies it isn't possible to speak about self-determined study process where self-assessment plays a significant role. Self-assessment in essence is consciousness of one's own knowledge limitations which is one of critical thinking principles that serves as a reference point for further development. First-year student personal reflection indicates lack of experience and of strong sides and actualizes missing knowledge by critically perceiving and analyzing educational opportunities offered by specific course material. In the beginning of studies, student's evaluative actions lack systemicity, structural certainty and succession. They are rather incidental (situational) and lack flexibility and objectivity.

By developing their assessment skills of decisions made by themselves and others, students strengthen their inner feedback which gradually allows them to supervise and evaluate their own studies independently of lecturers (Nicol, 2013). Self-assessment experience integrates into their structure of learning skills, therefore study process cannot be confined to just traditional evaluation forms and evaluation of the lecturer is a way of gaining this experience and an objective indicator for comparing self-assessment (Žogla, 2001). Self-assessment as an evaluative action is an important part of the study process since it motivates to 
learn. Self-assessment as reflection, in turn, promotes recognizing goals and making corrections to optimize the study process.

In order to ensure further development of student competences it is necessary to perform an analysis of the initial situation, to self-assess existing experiencebased knowledge and skills and to determine current study requirements. By motivating students to objectively assess their personal investment it is possible to lessen the inertness and passiveness of young people by substituting it with personal reflection.

\section{Research results}

The described research analyzes information perception, analyzing and structuring skills of first-year students in the Medical faculty in Rịga Stradiňš University. Research shows the most effective forms of work and student views on different variants of course presentation. The research compares two variables: student answers in questionnaires in the beginning and the end of the semester. Based on the results of the mentioned questionnaires, regularities were found and analyzed, allowing to determine the effectiveness of study material and didactic model based on critical thinking principles. The study was conducted in several stages. During the concluding phase of the situational awareness study, the most effective forms of work or distractions, medical students' perceptions of study, and motivation to study chemistry were identified. To this end, students expressed their thoughts in small essays.

Based on the analysis of these essays, questionnaire questions were formulated for further study of the situation. During the formative phase, the obtained data were systematized and analysed, the pedagogical conditions ensuring the acquisition of the chemistry course were specified: pedagogical activity, organizational forms, methods and means, psychological and emotional influence and personal experience consisting of creative, cognitive and emotional components. The questionnaire was distributed both electronically and in writing to increase the number of respondents involved. In the final phase of the research, the results of the questionnaire analysis were interpreted. Based on the results of the questionnaires, the established relationships were analyzed, working methods were corrected and the effectiveness of the didactic model based on the study material and critical thinking principles was determined.

Achieved study results were determined based on developed criteria for Medical chemistry course material and respective critical thinking levels determined by questionnaires and results of the final test - exam.

Only 25\% - 50\% of questioned students agree that the study process consists of information gathering and analysis. Results of questionnaires show that students have little skill in analyzing large amounts of information. Experience 
gained in school is mostly related to remembering and reproducing ready-made conclusions. This situation increases the need for problem-solving skills and information systematization. It is, therefore, necessary to emphasize the significance of the evaluation of information sources and problem-solving at the beginning of the study process while also combining it with other critical thinking development methods.

By knowing that visual representation of the same process can differ in different sources, students must have their own "interpretation" of processes. Results of questionnaires show that $61 \%$ - $99 \%$ of questioned students prefer the new information to be visually quick to understand as opposed to broad descriptive texts. At the same time, however, some of the students have difficulties with perceiving schemas due to lack of elementary knowledge in chemistry. The developed study materials justify regularities with examples that are understandable to medics and show medical problems as chemical processes that take place in the human body along with their causes and consequences. Understanding of causes and consequences also helps students to develop information systemization and analysis skills.

Comprehensive knowledge can only be obtained by integration of theoretical knowledge in practical work. Within the didactic model developed in a chemistry course, students learn to analyze new and already known facts during seminars and laboratory work. Development of critical thinking skills creates individual responsibility for results and their interpretation. Practical and laboratory work dedicated to specific topic becomes a part of a connected study process that interleaves with previous work and creates the groundwork for future work. Practical and laboratory work also indicate what knowledge is lacking in order to connect theoretical foundation with practical methods.

Regularities described in theoretical material materialize into specific and predictable forms in laboratory work. This is confirmed by $92,2 \%-96,7 \%$ positive answers in the questionnaires at the end of the semester over the research period of six years. Research methods provide a notion of the main analytical methods used in clinical laboratories (93,5\% - 97,8\%). By learning to carry our universal manipulations in a laboratory using simple specimens, students gain a concept of highly specialized clinical examinations.

By analyzing student success in solving problem-tasks and problemsituations and result of questionnaires it can be concluded that problem solving is an effective component of the didactic model. Different experience in problemtask solution doesn't prohibit students to effectively work with problems provided in chemistry course since questionnaires at the end of the semester over a period of six years show that $80 \%-84 \%$ respondents answer affirmatively. Ability to analyze problems, evaluate information and adequately assess one's own skills and limitations becomes more important than knowledge of individual facts. 
For self-assessment at the end of the semester positive answers in questionnaires range from $79 \%$ to $92,6 \%$. Unfortunately in the first semester it isn't yet possible to speak of adequate self-assessment as a way to increase study productivity and a way to improve as a person. The need for improvement is indicated by the awareness of study significance that is driven by a motivation to make studies self-determined although from an organizational standpoint they may be regulated by outer factors.

\section{Conclusions}

The results of the questionnaire allow concluding that a didactic model which is based on critical thinking principles changes student attitude towards medical chemistry course transforming the course from just another subject into a tool that allows integrating fundamental knowledge in other fields. Medical chemistry course includes examples from different fields where critical information analysis allows students to see interdisciplinary relationships thus making students aware of an integrative unification between aspects of theoretical and clinical disciplines.

Questionnaire results provide feedback and illustrate trends in study process during the semester:

- $\quad$ Students are motivated to independently create their own study material by using the provided study material together with other sources of information, to plan tasks according to their level of expertise and to critically evaluate and conclude what other information is necessary in addition to provided information.

- Representation of causes and consequences, comparison and opposition of concepts, the depiction of quantitative solutions, understanding something in its essence - all can be learned and developed in practical and laboratory work using visual information representation techniques.

- The research actualizes the use of thorough but concise information and potential uses of graphical information organizers for further development of analytical and interpretation skills.

- $\quad$ By analyzing research results it can be concluded that problem-solving in chemistry course during the first semester develops fact selection, analysis, detection of contradictions and errors (made by themselves and others) and their evaluation and correction.

- A significant amount of students agrees that self-assessment as an evaluative action is an integral part of the study process, however during the semester development of self-assessment had not been observed. 
- Theoretical study material provides the ability to master medical chemistry course for motivated students with different levels of preparedness while also developing knowledge construction skills that are based on constructive models. Finding solutions which are based on facts and their further interpretation not only ensures success but also motivates students to improve their study experience.

\section{References}

Budke, A., \& Meyer, M. (2015). Fachlich argumentieren lernen - Die Bedeutung der Argumentation in den unterschiedlichen Schulfächern (9-28). Budke, A., Kuckuck, M., Meyer, M., Schäbitz, F., Schlüter, K., Weiss, Günther [Hrsg.] Fachlich argumentieren lernen. Didaktische Forschungen zur Argumentation in den Unterrichtsfächern. LehrerInnenbildung gestalten, Hrsg. Vom Zentrum für LehrerInnenbildung der Universität zu Köln.

Cockerham, W., Dingwall, R., \& Quah, S. (2014). The Wiley-Blackwell encyclopedia of health, illness, behavior, and society / edited by William C. Cockerham, Robert Dingwall, and Stella Quah. Chichester, West Sussex. UK: Wiley-Blackwell.

Floridi, L. (2010). Information: A Very Short Introduction. Oxford University Press. ProQuest Ebook Central. Retrieved from http://ebookcentral.proquest.com.db.rsu.lv

Huitt, W. (1992). Problem solving and decision making: Consideration of individual differences using the Myers-Briggs Type Indicator. Journal of Psychological Type, 24, 33-44. Retrieved from http://www.edpsycinteractive.org/papers/prbsmbti.html

Jenicek, M. (2006). The hard art of soft science: Evidence-Based Medicine, Reasoned Medicine or both? Journal of Evaluation In Clinical Practice, 12(4), 410-419. DOI:10.1111/j.1365-2753.2006.00718.x

Kallet, M. (2014). Think smarter: Critical thinking to improve problem-solving and decisionmaking skills. John Wiley \& Sons, Incorporated. Retrieved from https://ebookcentralproquest-com.db.rsu.lv

Manarin, K., Carey, M., Rathburn, M., \& Ryland, G. (2015). Critical reading in higher education: academic goals and social engagement. Indiana University Press. Retrieved from https://ebookcentral-proquest-com.db.rsu.lv

Nicol, D. (2013). Resituating feedback from the reactive to proactive. In D. Boud \& E.Molloy (Eds.), Feedback in Higher and Professional Education: Understanding It and Doing It Well (pp. 34-49). Oxon, UK: Routledge.

Paul, R., \& Elder, L. (2002). Critical thinking: Tools for taking charge of your professional and personal life. Financial Times Prentice Hall.

Paul, R., \& Elder, L. (2012). Critical thinking: Competency standards essential to the cultivation of intellectual skills, part 5. Journal of Developmental Education, 36(1), 30-31. Retrieved from http://search.proquest.com/docview/1285469423?accountid=32994

Paul, R., \& Elder, L., (2011). Critical thinking: Competency standards essential for the cultivation of intellectual skills, part 3. Journal of Developmental Education, 35(2), 3435. Retrieved from http://search.proquest.com/docview/1023133581?accountid=32994

Rubene Z., \& Svece A. (2018). Kritiskās domāšanas attīstīšana izglītībā Latvijā: situācijas analīze un pilnveides perspektīvas. No M. Kūle, u. c. Kritiskā domāšana: izglītība, medijpratība un spriestspēja (13-24). Rīga: LU Filozofijas un socioloǵijas institūts. 
SOCIETY. INTEGRATION. EDUCATION

Proceedings of the International Scientific Conference. Volume I, May $22^{\text {th }}-23^{\text {th }}, 2020.350-362$

Tennyson, R. Defining a learning theory linked to instructional theory interactive cognitive model. In: Beck, K., \& Zlatkin-Troitschanskaia, O. (Eds.). (2013). From diagnostics to learning success: Proceedings in vocational education and training. Retrieved from https://search-proquest-com.db.rsu.lv

Thomas, P., \& Abras, C. (2016). Thomas, P., Kern, D., Hughes, M., \& Chen, B. (Eds.). Curriculum development for medical education: a six-step approach. Chapter 5. 65-101. Retrieved from https://ebookcentral-proquest-com.db.rsu.lv

Volkov, E. (2004). Kriticheskoe myshlenie: principy i priznaki. Retrieved from http://scepticratio.narod.ru/ps/volkov.htm

Žogla, I. (2001). Didaktikas teorētiskie pamati. Rīga, Izdevniecība RaKa. 